Virginia Commonwealth University

vCU Scholars Compass

2002

\title{
Voriconazole Compared with Liposomal Amphotericin B for Empirical Antifungal Therapy in Patients with Neutropenia and Persistent Fever
}

Thomas J. Walsh

National Cancer Institute

Peter Pappas

University of Alabama - Birmingham

Drew J. Winston

University of California - Los Angeles

See next page for additional authors

Follow this and additional works at: http://scholarscompass.vcu.edu/vcuhealth_pubs

Part of the Medicine and Health Sciences Commons

From the New England Journal of Medicine, Walsh, T. J., Pappas, P., Winston D. J. et al., Voriconazole Compared with Liposomal Amphotericin B for Empirical Antifungal Therapy in Patients with Neutropenia and Persistent Fever, Vol. 346, Page 225, Copyright (C) 2002 Massachusetts Medical Society. Reprinted with permission.

Downloaded from

http://scholarscompass.vcu.edu/vcuhealth_pubs/20

This Article is brought to you for free and open access by the VCU Health at VCU Scholars Compass. It has been accepted for inclusion in VCU Health Publications by an authorized administrator of VCU Scholars Compass. For more information, please contact libcompass@vcu.edu. 


\section{Authors}

Thomas J. Walsh, Peter Pappas, Drew J. Winston, Hillard M. Lazarus, Finn Petersen, John Raffalli, Saul Yanovich, Patric Stiff, Richard Greenberg, Gerald Donowitz, and Jeanette Lee 


\title{
The New England Journal of Medicine
}

Copyright (C) 2002 by the Massachusetts Medical Society

VOLUME 346

JANUARY 24, 2002

NUMBER 4

\section{VORICONAZOLE COMPARED WITH LIPOSOMAL AMPHOTERICIN B FOR EMPIRICAL ANTIFUNGAL THERAPY IN PATIENTS WITH NEUTROPENIA AND PERSISTENT FEVER}

\author{
Thomas J. Walsh, M.D., Peter Pappas, M.D., Drew J. Winston, M.D., Hillard M. Lazarus, M.D., \\ Finn Petersen, M.D., John Raffalli, M.D., Saul Yanovich, M.D., Patrick Stiff, M.D., \\ Richard Greenberg, M.D., Gerald Donowitz, M.D., and Jeanette Lee, Ph.D., \\ for the National Institute of Allergy and Infectious Diseases Mycoses Study Group*
}

\begin{abstract}
Background Patients with neutropenia and persistent fever are often treated empirically with amphotericin B or liposomal amphotericin B to prevent invasive fungal infections. Antifungal triazoles offer a potentially safer and effective alternative.

Methods In a randomized, international, multicenter trial, we compared voriconazole, a new second-generation triazole, with liposomal amphotericin $B$ for empirical antifungal therapy.

Results A total of 837 patients (415 assigned to voriconazole and 422 to liposomal amphotericin B) were evaluated for success of treatment. The overall success rates were 26.0 percent with voriconazole and 30.6 percent with liposomal amphotericin B $(95$ percent confidence interval for the difference, -10.6 to 1.6 percentage points); these rates were independent of the administration of antifungal prophylaxis or the use of colony-stimulating factors. There were fewer documented breakthrough fungal infections in patients treated with voriconazole than in those treated with liposomal amphotericin B (8 [1.9 percent] vs. 21 [5.0 percent], $P=0.02$ ). The voriconazole group had fewer cases of severe infusion-related reactions $(P<0.01)$ and of nephrotoxicity $(P<0.001)$. The incidence of hepatotoxicity was similar in the two groups. Patients receiving voriconazole had more episodes of transient visual changes than those receiving liposomal amphotericin $B(22$ percent vs. 1 percent, $\mathrm{P}<0.001$ ) and more hallucinations (4.3 percent vs. 0.5 percent, $\mathrm{P}<0.001$ ). Parenteral voriconazole was changed to the oral formulation in 22 percent of the voriconazole group, with a reduction in the mean duration of hospitalization by one day in all patients $(P=0.17)$ but by two days in patients at high risk $(\mathrm{P}=0.03)$.

Conclusions Voriconazole is a suitable alternative to amphotericin B preparations for empirical antifungal therapy in patients with neutropenia and persistent fever. (N Engl J Med 2002;346:225-34.)

Copyright (C) 2002 Massachusetts Medical Society.
\end{abstract}

$\mathrm{I}$ NVASIVE fungal infections are important causes of morbidity and mortality among patients receiving cancer chemotherapy or undergoing bone marrow or stem-cell transplantation..$^{1-3}$ Over the past two decades, empirical antifungal therapy with conventional amphotericin B or liposomal amphotericin B has become the standard of care in reducing invasive fungal infections in patients with neutropenia and persistent fever. ${ }^{4-9}$ Amphotericin B, however, is associated with significant dose-limiting nephrotoxicity and infusion-related reactions. Liposomal amphotericin $\mathrm{B}$ is equivalent to conventional amphotericin B for use as empirical antifungal therapy and significantly reduces proven invasive fungal infections, nephrotoxicity, and infusion-related reactions. ${ }^{10,11}$ The high acquisition cost of liposomal amphotericin B, however, has limited the use of this less toxic formulation of amphotericin B. Moreover,

From the National Cancer Institute, Bethesda, Md. (T.J.W.); the University of Alabama, Birmingham (P.P.); the University of California, Los Angeles (D.J.W.); the University Hospitals of Cleveland, Cleveland (H.M.L.); the University of Utah, Salt Lake City (F.P.); New York Medical College, New York (J.R.); the Medical College of Virginia, Richmond (S.Y.); Loyola University Medical Center, Chicago (P.S.); the University of Kentucky, Lexington (R.G.); the University of Virginia, Charlottesville (G.D.); and the National Institute of Allergy and Infectious Diseases Mycoses Study Group, Birmingham, Ala. (J.L.). Address reprint requests to Dr. Walsh at the Immunocompromised Host Section, National Cancer Institute, Bldg. 10, Rm. 13N240, Bethesda, MD 20892.

Other authors were Mindy Schuster, M.D. (University of Pennsylvania, Philadelphia); Annette Reboli, M.D. (Cooper Hospital, Camden, N.J.); John Wingard, M.D. (University of Florida, Gainesville); Carola Arndt, M.D. (Mayo Clinic, Rochester, Minn.); John Reinhardt, M.D. (Medical Center of Delaware, Newark); Susan Hadley, M.D. (Beth Israel Deaconess Medical Center, Boston); Robert Finberg, M.D. (Dana-Farber Cancer Institute, Boston); Michél Laverdière, M.D. (Maisonneuve-Rosemont Hospital, Montreal); John Perfect, M.D. (Duke University, Durham, N.C.); Gary Garber, M.D. (University of Ottawa, Ottawa, Ont., Canada); Giuseppe Fioritoni, M.D. (Ospedaliero della ASL di Pescara, Pescara, Italy); and Eli Anaissie, M.D. (University of Arkansas, Little Rock).

*Other participants in the study are listed in the Appendix. 
breakthrough fungal infections, infusion-related reactions, and nephrotoxicity still occur in patients receiving liposomal amphotericin B.

Antifungal triazoles are promising agents for empirical antifungal therapy. ${ }^{12,13}$ Fluconazole has been studied for this indication, but its use is limited because it has a narrow antifungal spectrum restricted to yeasts. ${ }^{14-16}$ Itraconazole also has been investigated. ${ }^{17}$ However, its oral administration is limited because of the erratic bioavailability of the capsule form and the adverse gastrointestinal effects of the oral solution. Moreover, there has been limited experience with the new parenteral formulation. The new generation of antifungal triazoles that includes voriconazole has a broad in vitro spectrum, potent in vivo activity, a favorable safety profile, and excellent bioavailability. ${ }^{18-20}$ We reasoned that voriconazole, a second-generation triazole, might be as effective as conventional or liposomal amphotericin B for empirical antifungal therapy, but less toxic.

\section{METHODS}

\section{Study Design}

The study was an open-label, prospective, randomized, multicenter, international comparative trial of voriconazole and liposomal amphotericin B, conducted between March 1998 and September 1999. The study was reviewed by an institutional review board or ethics committee at each of the 73 participating centers. Written informed consent was obtained from each patient or his or her legal guardian before enrollment in the study. The data safety and monitoring board of the National Institute of Allergy and Infectious Diseases Mycoses Study Group was convened to review data in order to monitor patient safety. A data-review committee composed of a panel of blinded investigators with expertise in the study and treatment of fungal infections reviewed and classified all documented (proven and probable) fungal infections, using protocol-defined criteria. ${ }^{21}$

\section{Enrollment, Stratification, and Randomization}

Eligible patients were at least 12 years of age; had received chemotherapy for leukemia, lymphoma, or other cancers or had undergone transplantation of hematopoietic stem cells; and had received more than 96 hours of systemic antibacterial therapy while continuing to have fever (oral temperature above $38^{\circ} \mathrm{C}$ within 24 hours before randomization) and neutropenia (an absolute neutrophil count below 500 cells per cubic millimeter for 96 hours and below 250 cells per cubic millimeter within 24 hours before randomization). Patients were not eligible if they had a documented invasive fungal infection at the time of randomization or serum levels of aspartate aminotransferase, alanine aminotransferase, alkaline phosphatase, or bilirubin that were more than five times the upper limit of normal.

Patients at each center were stratified according to their degree of risk for fungal infection and the use or nonuse of systemic antifungal prophylaxis. Patients were randomly assigned to receive either voriconazole or liposomal amphotericin $\mathrm{B}$, in a $1: 1$ ratio, according to a computer-generated randomization system with a two-perblock design. Patients at high risk were defined as those who had received allogeneic hematopoietic stem-cell transplants or who were receiving chemotherapy for relapsed leukemia. Other patients were classified as being at moderate risk.

\section{Administration of Study Drugs}

Voriconazole was administered intravenously on day 1 as a loading dose of $6 \mathrm{mg}$ per kilogram of body weight every 12 hours for two doses and then continued at a maintenance dose of $3 \mathrm{mg}$ per kilogram intravenously every 12 hours (or $200 \mathrm{mg}$ orally every 12 hours, after at least three days of intravenous therapy). Liposomal amphotericin B was initiated and continued at $3 \mathrm{mg}$ per kilogram intravenously per day. After protocol-defined guidelines for evidence of fungal infection had been met, investigators were permitted to increase the dose of voriconazole to $4 \mathrm{mg}$ per kilogram intravenously every 12 hours or $300 \mathrm{mg}$ orally every 12 hours and the dose of liposomal amphotericin $\mathrm{B}$ to $6 \mathrm{mg}$ per kilogram intravenously per day. If toxic effects occurred, lowering of the dose of liposomal amphotericin B to $1.5 \mathrm{mg}$ per kilogram per day was permitted. No dose reduction was permitted for voriconazole unless there had been a prior dose escalation. On the basis of the assessment of the primary physician, patients who were unable to tolerate or did not respond to the study drug were removed from the clinical trial. Patients continued therapy for up to 3 days after neutrophil recovery (defined as an absolute neutrophil count of at least 250 cells per cubic millimeter), or up to a maximum of 12 weeks in those with documented invasive fungal infections. All infusion-related reactions were monitored prospectively with a previously validated bedside monitoring form.

\section{Antifungal Activity and Pharmacokinetics of Voriconazole}

Minimal inhibitory concentrations of voriconazole and amphotericin $\mathrm{B}$ were determined in a central reference laboratory according to the guidelines of the National Committee for Clinical Laboratory Standards ${ }^{22,23}$ for yeasts and filamentous fungi isolated from patients with documented invasive fungal infections. Plasma voriconazole levels were determined in each patient by high-performance liquid chromatography of blood collected twice weekly, according to a minimal sampling strategy. ${ }^{24}$

\section{Composite Outcome Score}

Treatment was considered successful if the patient did not have a breakthrough fungal infection, survived for seven days beyond the end of therapy, did not discontinue therapy prematurely, had resolution of fever during the period of neutropenia, and was successfully treated for any base-line fungal infection. Encompassing at least one end point from each earlier trial, ${ }^{6-8,11,14,15}$ this composite scoring system has been used and validated in other studies of empirical antifungal therapy. ${ }^{10,16,17}$ Secondary analyses of individual composite end points were exploratory assessments and were not intended to be a primary determination of outcome superiority.

\section{Statistical Analysis}

Noninferiority was predefined as a difference in success rates between voriconazole and liposomal amphotericin B of no more than 10 percentage points. On the assumption of a success rate of 50 percent, a sample of 393 patients who could be evaluated in each treatment group (a total of 786) was required to demonstrate noninferiority at the two-sided significance level of 5 percent with a power of 80 percent. ${ }^{25}$ Thus, a 95 percent confidence interval for the difference in response rates within 10 percentage points in either direction was required for voriconazole to be considered not inferior to liposomal amphotericin B. On the assumption of a 10 percent loss of patients from the modified intention-to-treat population, a total sample size of 866 needed to be enrolled. The population for the primary analysis (the modified intention-to-treat population) was defined as the patients who were randomly assigned to treatment, who received one or more doses of study drug, and for whom the data were sufficient to permit evaluation. The sample was also sufficiently large that the study was prospectively projected to assess the effect of the study drug on the prevention of invasive fungal infections, given the assumption of a 6 percent frequency of infection, a reduction to 2 percent, and a two-tailed alpha level of 0.05 . 
Outcome indicators were analyzed on the basis of the confidence interval around the difference in success rates and by the Cochran-Mantel-Haenszel chi-square test in the modified intention-to-treat population. A 95 percent two-sided confidence interval was constructed around the difference in success rates between the two treatment groups. The rates of adverse events and other safety-related variables were tabulated according to treatment group, and selected variables were analyzed by the chi-square test or Fisher's exact test. A Kaplan-Meier analysis of time to defervescence was plotted.

The patients' utilization of health care resources was prospectively studied. We hypothesized that the availability of the oral formulation of voriconazole would lead to earlier hospital discharge. The total number of inpatient days was analyzed by the Wilcoxon rank-sum test (two-sided).

\section{RESULTS}

\section{Patient Population}

A total of 849 patients received at least one dose of study drug. Among the 837 patients in the modified intention-to-treat population, 415 received voriconazole and 422 received liposomal amphotericin B. The study groups were similar with regard to age, sex, race, underlying primary neoplastic disease, and risk of fungal infection (Table 1). Antibacterial therapy, including use of aminoglycosides, use of antiviral agents, and modifications of initial antibiotic therapy, was also similar in the two treatment groups. Thirteen patients in the voriconazole group and six patients in the liposomal amphotericin B group had base-line fungal infections documented within the first 24 hours after entry to the study (Table 1).

\section{Efficacy}

The overall success rate according to the composite score and the response according to each of its five components are shown in Table 2. The overall success rate among patients in the modified intention-to-treat population was 26.0 percent for those receiving voriconazole and 30.6 percent for those receiving liposomal amphotericin B (95 percent confidence interval for the difference, -10.6 to 1.6 percentage points). This 95 percent confidence interval falls just outside the predefined lower limit of -10 percentage points. Among the five components in the composite score, the only significant difference was found in the frequency of breakthrough fungal infections.

Documented breakthrough fungal infections occurred in 8 patients receiving voriconazole and 21 patients receiving liposomal amphotericin $\mathrm{B}(\mathrm{P}=$ 0.02 ) (Table 3). There were fewer cases of documented breakthrough invasive aspergillosis, candidemia, and dematiaceous mold infections among patients receiving voriconazole, and fewer cases of zygomycosis among patients receiving liposomal amphotericin B. We further evaluated the effect of breakthrough fungal infections by examining 30-day mortality. Among the 29 patients with breakthrough fungal infections, 14 (48.3 percent) died from invasive mycosis; in comparison, the overall mortality in this study was 12.9 percent (108 of $837, \mathrm{P}<0.001$ ).

The reduction in invasive fungal infections was particularly apparent in the stratified cohort of patients at high risk (those with allogeneic transplants or relapsed leukemia) (Table 4). Among these patients, those receiving voriconazole had fewer documented breakthrough fungal infections than those receiving liposomal amphotericin B (2 of 143 [ 1.4 percent] vs. 13 of 141 [9.2 percent], $\mathrm{P}=0.003)$. The protective effect of voriconazole was also evident in the highrisk population among patients who were receiving systemic antifungal prophylaxis: 1.2 percent of these patients had invasive fungal infections, as compared with 9.1 percent in the liposomal amphotericin B group $(\mathrm{P}=0.02)$

The most common documented base-line fungal infection was candidemia, followed by pulmonary aspergillosis, disseminated zygomycosis, and trichoderma fungemia. Similar proportions of base-line fungal infections responded to voriconazole and liposomal amphotericin B (6 of 13 [46.2 percent] and 4 of 6 [66.7 percent], respectively; $\mathrm{P}=0.63$ ) (Table 2).

There was no significant difference in overall mortality between the voriconazole and liposomal amphotericin B groups. However, among the patients who died, more patients in the voriconazole group than in the liposomal amphotericin B group died of progressive underlying neoplastic disease (13 vs. 5 , $\mathrm{P}=0.06$ ). There were also more deaths from bacterial pneumonia or sepsis among the patients with progressive cancer.

There was a trend toward more frequent premature discontinuation of the study drug in the voriconazole group than in the liposomal amphotericin $\mathrm{B}$ group. The number of patients discontinuing the drug because of toxic effects was similar in the two groups ( 19 in the voriconazole group and 23 in the liposomal amphotericin B group). However, there were more discontinuations due to lack of efficacy in patients who received voriconazole $(22$ vs. $5, \mathrm{P}=$ 0.001 ), with persistent fever being the most common reason for withdrawal ( 14 vs. $2, \mathrm{P}=0.002$ ). None of these fevers were due to documented breakthrough fungal infections. Despite these withdrawals because of fever, the overall frequency of resolution of fever and the time to resolution of fever were virtually identical in the two study groups according to Kaplan-Meier analysis (Fig. 1).

\section{Effect of Risk Stratification on Outcome}

Among patients at high risk, the overall success rate was 32 percent for voriconazole and 30 percent for 
Table 1. Demographic and Clinical Characteristics of the Study Patients.*

Characteristic

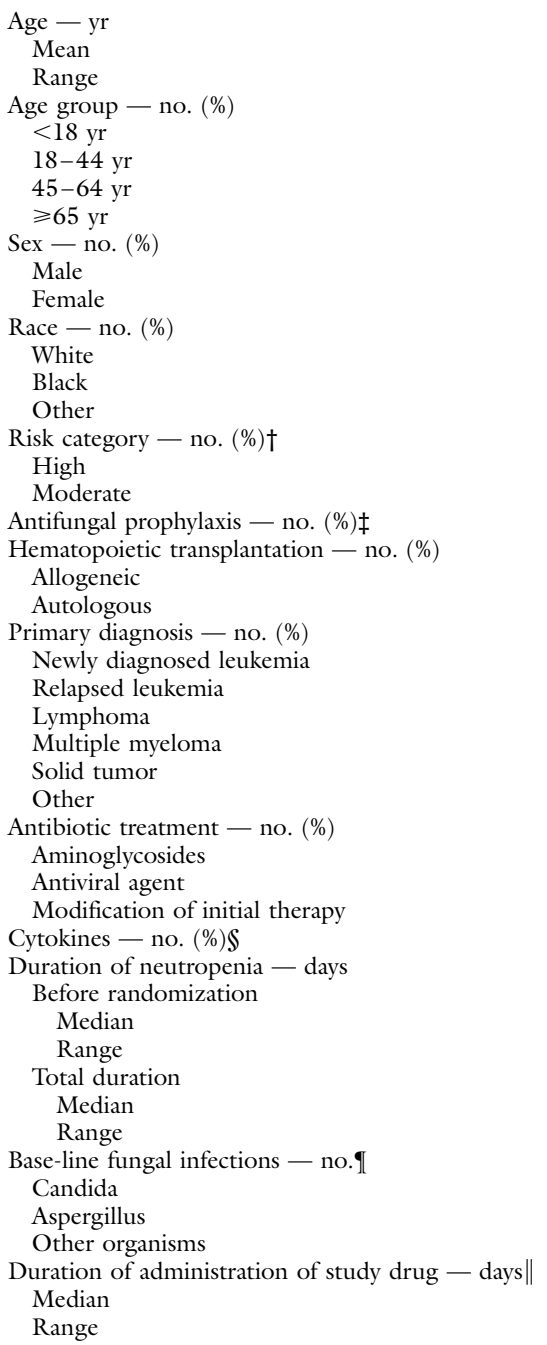

\begin{tabular}{|c|c|}
\hline $\begin{array}{l}\text { VORICONAZOLE } \\
\quad(\mathrm{N}=\mathbf{4 1 5})\end{array}$ & $\begin{array}{l}\text { LIPOSOMAL AMPHOTERICIN B } \\
(\mathrm{N}=422)\end{array}$ \\
\hline $\begin{array}{c}46.3 \\
12-82\end{array}$ & $\begin{array}{c}45.0 \\
12-80\end{array}$ \\
\hline $\begin{array}{r}13(3.1) \\
161(38.8) \\
190(45.8) \\
51(12.3)\end{array}$ & $\begin{array}{r}20(4.7) \\
177(41.9) \\
181(42.9) \\
44(10.4)\end{array}$ \\
\hline $\begin{array}{l}233(56.1) \\
182(43.9)\end{array}$ & $\begin{array}{l}216(51.2) \\
206(48.8)\end{array}$ \\
\hline $\begin{array}{c}325(78.3) \\
35(8.4) \\
55(13.3)\end{array}$ & $\begin{array}{c}333(78.9) \\
32(7.6) \\
57(13.5)\end{array}$ \\
\hline $\begin{array}{r}143(34.5) \\
272(65.5) \\
222(53.5) \\
198(47.7) \\
76(18.3) \\
122(29.4)\end{array}$ & $\begin{array}{r}141(33.4) \\
281(66.6) \\
250(59.2) \\
217(51.4) \\
79(18.7) \\
139(32.9)\end{array}$ \\
\hline $\begin{array}{r}130(31.3) \\
92(22.2) \\
57(13.7) \\
22(5.3) \\
52(12.5) \\
62(14.9)\end{array}$ & $\begin{array}{r}130(30.8) \\
84(19.9) \\
63(14.9) \\
24(5.7) \\
58(13.7) \\
63(14.9)\end{array}$ \\
\hline $\begin{array}{r}199(48.0) \\
277(66.7) \\
66(15.9) \\
192(46.3)\end{array}$ & $\begin{array}{r}216(51.2) \\
297(70.4) \\
75(17.8) \\
201(47.6)\end{array}$ \\
\hline $\begin{array}{c}7.7 \\
2.4-71\end{array}$ & $\begin{array}{c}7.6 \\
2.4-60\end{array}$ \\
\hline $\begin{array}{c}15.2 \\
3.3-119 \\
13 \\
10 \\
2 \\
1\end{array}$ & $\begin{array}{c}14.2 \\
4.2-75 \\
6 \\
3 \\
2 \\
1\end{array}$ \\
\hline $\begin{array}{c}7 \\
1-113\end{array}$ & $\begin{array}{c}7 \\
1-81\end{array}$ \\
\hline
\end{tabular}

*Because of rounding, not all percentages add to 100

$\dagger$ Patients at high risk had undergone allogeneic hematopoietic transplantation or had relapsed leukemia. Among patients with relapsed leukemia, 31 of 92 patients receiving voriconazole ( 34 percent) and 27 of 84 patients receiving liposomal amphotericin B (32 percent) also underwent allogeneic hematopoietic transplantation.

$\ddagger$ Antifungal prophylaxis was defined as treatment with systemically absorbed or parenterally administered antifungal agents for the prevention of invasive fungal infections before randomization.

\$Cytokines were granulocyte colony-stimulating factor and granulocyte-macrophage colony-stimulating factor.

IInvasive fungal infections (as defined by modified criteria of the European Organization for Research and Treatment of Cancer-Mycosis Study Group ${ }^{21}$ ) documented within 24 hours after study entry are listed. One patient in the voriconazole group had disseminated zygomycosis, and one in the amphotericin B group had trichoderma fungemia at base line. Among patients with base-line fungal infections, 2 of 13 assigned to voriconazole ( 15 percent) received antifungal prophylaxis (fluconazole in both cases), and 3 of 6 assigned to liposomal amphotericin B (50 percent) received antifungal prophylaxis (fluconazole in 2 cases and low-dose deoxycholate amphotericin B in 1 case).

$\|$ Ninety-two patients (22 percent) received the oral formulation of voriconazole. 
Table 2. Response to Empirical Therapy.

\begin{tabular}{|c|c|c|c|}
\hline RESPONSE INDICATOR & $\begin{array}{l}\text { VORICONAZOLE } \\
\qquad(\mathbf{N}=\mathbf{4 1 5})\end{array}$ & $\begin{array}{l}\text { LIPOSOMAL } \\
\text { AMPHOTERICIN B } \\
\text { (N=422) }\end{array}$ & $\begin{array}{c}\text { Point Estimate for } \\
\text { the Percent Difference } \\
\text { (95\% Confidence INTERVAL) }\end{array}$ \\
\hline Overall response - no. (\%) & $108(26.0)$ & $129(30.6)$ & $-4.5(-10.6$ to 1.6$)$ \\
\hline $\begin{array}{l}\text { No breakthrough fungal infections within } 7 \text { days } \\
\text { of end of therapy }- \text { no. }(\%)\end{array}$ & $407(98.1)$ & $401(95.0)$ & $+3.1(0.6$ to 5.5$)$ \\
\hline $\begin{array}{l}\text { No discontinuation due to toxicity or lack of efficacy } \\
\text { before recovery from neutropenia - no. }(\%)\end{array}$ & $374(90.1)$ & $394(93.4)$ & $-3.2(-7.0$ to 0.5$)$ \\
\hline Resolution of fever during neutropenia - no. (\%) & $135(32.5)$ & $154(36.5)$ & $-4.0(-10.4$ to 2.5$)$ \\
\hline $\begin{array}{l}\text { Complete or partial response of patients with base-line fungal } \\
\text { infections by end of treatment }- \text { no./total no. }(\%)\end{array}$ & $6 / 13(46.2)$ & $4 / 6(66.7)$ & $-20.5(-67.0$ to 25.9$)$ \\
\hline
\end{tabular}

*The causes of death for patients in the voriconazole and liposomal amphotericin B groups, respectively, as assessed by the principal investigators, were as follows: progression of cancer (13 and 5 patients), respiratory failure (4 and 3 patients), renal failure (2 patients and 1 patient), sepsis (15 and 9 patients), bacterial pneumonia ( 7 patients and 1 patient), hemorrhage ( 0 and 6 patients), disseminated fungal infection ( 1 patient and 2 patients), ventricular fibrillation ( 1 patient and 0 ), and other causes ( 5 and 4 patients).

liposomal amphotericin B (95 percent confidence interval for the difference, -9.0 to 12.4 percentage points). By comparison, among patients at moderate risk, the overall success rate was lower for voriconazole ( 23 percent) than for liposomal amphotericin B (31 percent) (95 percent confidence interval for the difference, -15.2 to -0.4 percentage points). This difference in efficacy among patients at moderate risk was due mainly to a disparity in mortality from progressive cancer. Although these patients were at lower risk for invasive fungal infections, they were not at lower risk for death due to other causes, including cancer.

\section{Safety and Tolerability \\ Infusion-Related Reactions}

Abnormal vision characterized by a transient alteration in the perception of light was the most common infusion-related toxic effect of voriconazole (Table 5 ). This effect was observed most frequently at the time of the first infusion and disappeared during subsequent infusions. Patients receiving liposomal amphotericin B had more episodes of acute infusionrelated reactions than those receiving voriconazole.

\section{Hepatotoxicity and Nephrotoxicity}

There were no significant differences between the study groups in hepatotoxicity, as measured by elevations in serum aspartate aminotransferase, alanine aminotransferase, and alkaline phosphatase levels ( $\mathrm{Ta}-$ ble 5 ). Serum bilirubin levels were more commonly elevated in recipients of liposomal amphotericin B. There was a greater frequency of azotemia among patients receiving liposomal amphotericin $\mathrm{B}$, as de- fined by an elevation in the serum creatinine level to more than 1.5 times the base-line value; however, there was no significant difference in the frequency of serum creatinine levels that were more than two times the base-line value. There also was a greater frequency of moderate hypokalemia (defined as a serum potassium level $\leqslant 3.0 \mathrm{mmol}$ per liter) and severe hypokalemia ( $\leqslant 2.5 \mathrm{mmol}$ per liter) in patients receiving liposomal amphotericin B.

\section{Visual Hallucinations and Other Toxic Effects}

Visual hallucinations were more frequent in patients receiving voriconazole than in those receiving liposomal amphotericin B (18 [4.3 percent] vs. 2 [0.5 percent $], \mathrm{P}<0.001)$. In most cases these effects were distinct from infusion-related altered perception of light. There were no differences between the groups in the frequency of treatment-related rash or cardiacassociated adverse events.

\section{Use of Health Care Resources}

Ninety-two patients ( 22 percent) were able to receive the oral formulation of voriconazole. Patients receiving voriconazole had a nonsignificant reduction in the duration of hospitalization, with a median difference of one day $(\mathrm{P}=0.17)$. Patients at high risk (those with allogeneic transplants or relapsed leukemia) who received voriconazole had a significant reduction in the duration of hospitalization with a median difference of two days $(\mathrm{P}=0.03)$.

\section{Antifungal Activity and Pharmacokinetics of Voriconazole}

Mean plasma voriconazole levels between 2 and $4 \mu \mathrm{g}$ per milliliter were sustained throughout the 
Table 3. Documented Breakthrough Invasive Fungal INFECTIONS. *

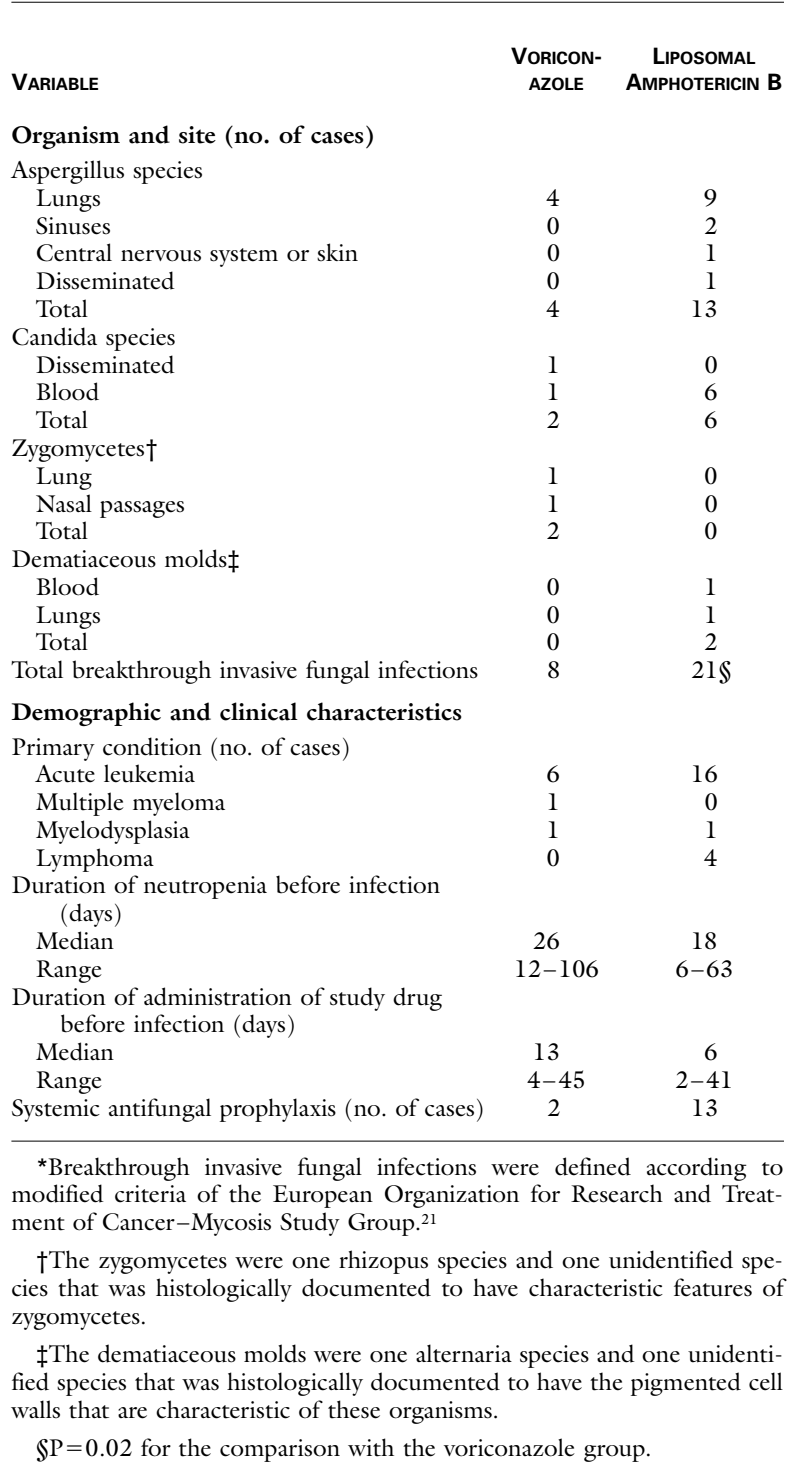

12-hour dosing interval. Approximately 75 percent of the plasma voriconazole levels were between 1 and $7 \mu \mathrm{g}$ per milliliter during the dosing interval. Among 15 isolates of candida species recovered from $10 \mathrm{pa}^{-}$ tients with fungemia, only 1 isolate (Candida glabrata) was associated with a minimal inhibitory concentration of voriconazole ( $4 \mu \mathrm{g}$ per milliliter) that exceeded plasma levels achieved by voriconazole at the dosages used in this study. This isolate was also resistant to other antifungal triazoles. Among five
Table 4. Documented Breakthrough Fungal Infections DURING EMPIRICAL ANTIFUNGAL THERAPY, According to Risk Category.

\begin{tabular}{|c|c|c|c|}
\hline \multirow[t]{2}{*}{ RISK Group } & $\begin{array}{l}\text { Antifungal } \\
\text { ProphyLAXIS* }\end{array}$ & $\begin{array}{c}\text { No } \\
\text { ANTIFUNGAL } \\
\text { ProphyLAXIS }\end{array}$ & TOTAL \\
\hline & \multicolumn{3}{|c|}{ no. of cases/total no. (\%) } \\
\hline \multicolumn{4}{|l|}{ High risk $†$} \\
\hline Voriconazole & $1 / 83 \quad(1.2)$ & $1 / 60 \quad(1.7)$ & $2 / 143(1.4) \ddagger$ \\
\hline $\begin{array}{l}\text { Liposomal ampho- } \\
\text { tericin B }\end{array}$ & $9 / 99 \quad(9.1)$ & $4 / 42 \quad(9.5)$ & $13 / 141(9.2) \ddagger$ \\
\hline \multicolumn{4}{|l|}{ Moderate risk } \\
\hline Voriconazole & $1 / 139(0.7)$ & $5 / 133(3.8)$ & $6 / 272(2.2) \$$ \\
\hline $\begin{array}{l}\text { Liposomal ampho- } \\
\text { tericin B }\end{array}$ & $4 / 151(2.6)$ & $4 / 130(3.1)$ & $8 / 281(2.8) \$$ \\
\hline \multicolumn{4}{|l|}{ Total } \\
\hline Voriconazole & $2 / 222(0.9)$ & $6 / 193(3.1)$ & $8 / 415(1.9) \mathbb{I}$ \\
\hline $\begin{array}{l}\text { Liposomal ampho- } \\
\text { tericin B }\end{array}$ & $13 / 250(5.2)$ & $8 / 172(4.7)$ & $21 / 422(5.0) \mathbb{I}$ \\
\hline
\end{tabular}

*Antifungal prophylaxis was defined as treatment with systemically absorbed or parenterally administered antifungal agents for the prevention of invasive fungal infections before randomization.

†Patients at high risk had undergone allogeneic hematopoietic transplantation or had relapsed leukemia.

$\ddagger \mathrm{P}=0.003$ for the comparison of voriconazole with amphotericin $\mathrm{B}$.

§P not significant.

$\mathbb{I} \mathrm{P}=0.02$ for the comparison of voriconazole with amphotericin $\mathrm{B}$.

isolates of aspergillus species, the minimal inhibitory concentration of voriconazole was within achievable levels.

\section{DISCUSSION}

In this randomized comparison of voriconazole with liposomal amphotericin B for empirical antifungal therapy in patients with neutropenia and persistent fever, voriconazole did not fulfill the protocol-defined criteria for noninferiority to liposomal amphotericin $\mathrm{B}$ with respect to overall response to empirical therapy, since the 95 percent confidence limit of -10.6 percentage points fell just outside the predefined lower bound of -10 percentage points. However, examination of the individual elements of the composite score for success indicated that the two treatments were similar and that voriconazole was superior in reducing documented breakthrough fungal infections, infusion-related toxicity, and nephrotoxicity.

The activity of voriconazole in the prevention of breakthrough fungal infections in this study is consistent with its efficacy in a recently completed clinical trial involving primary treatment of documented invasive aspergillosis. ${ }^{26}$ These effects may be related to the combination of its potent in vitro antifungal activity (indicated by low minimal inhibitory concentrations against most yeasts and filamentous fungi) 


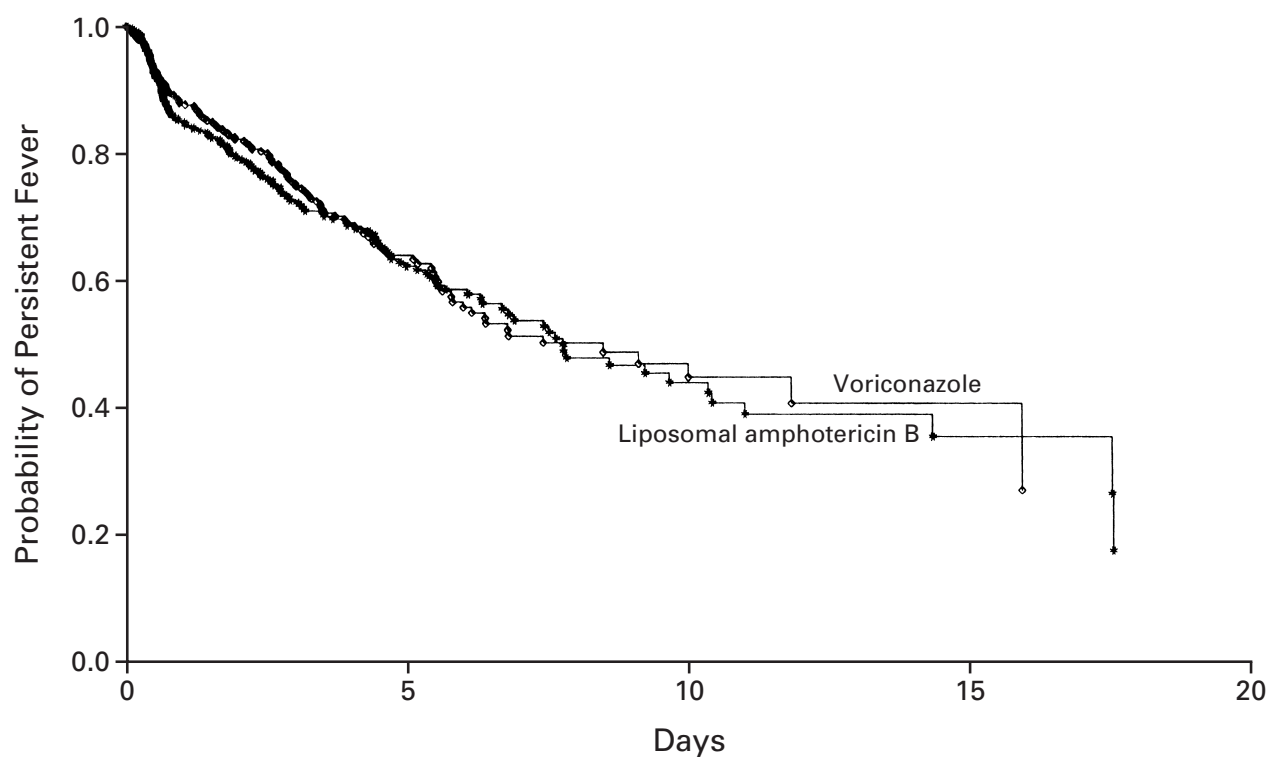

Figure 1. Kaplan-Meier Estimates of the Time to Resolution of Fever in Patients with Neutropenia and Persistent Fever Who Were Randomly Assigned to Receive Voriconazole or Liposomal Amphotericin B as Empirical Antifungal Therapy.

and its pharmacokinetic properties. ${ }^{12,13,26-28}$ The low molecular weight of voriconazole (349.3) may permit penetration into the endobronchial-lining fluid and other mucosal surfaces. ${ }^{28}$ The fact that the plasma pharmacokinetics in our study demonstrated circulating voriconazole levels well above the minimal inhibitory concentration for most fungal pathogens during its 12-hour dosing interval may also contribute to its clinical antifungal activity.

Empirical antifungal therapy with voriconazole should be used in patients with persistent neutropenia, who are at high risk for invasive antifungal infections. ${ }^{29-32}$ In the prospectively defined high-risk group in our study, the overall response rate among patients who received voriconazole was similar to the rate among those who received liposomal amphotericin B, and the frequency of breakthrough fungal infections was significantly reduced in the voriconazole group.

The open-label design of this trial permitted us to evaluate the effect of oral voriconazole on time of discharge, but it may have created a bias in favor of liposomal amphotericin B, with which there is extensive clinical experience. Significantly more patients receiving voriconazole than those receiving liposomal amphotericin B were removed prematurely from the study because of persistent fever in the absence of evidence of fungal infection, despite similar frequencies of fever in both groups. A similar pattern was seen in a large, randomized, open-label study comparing amphotericin B and fluconazole for candidemia, in which patients receiving fluconazole were removed from the study because of persistent fever, despite clinical stability and repeatedly negative blood cultures. ${ }^{33}$

In this study, the infusion-related reactions to voriconazole and liposomal amphotericin B were characterized by prospective bedside monitoring of more than 10,000 infusions. Although liposomal amphotericin B is well known to have significantly lower infusion-related toxicity than conventional amphotericin $\mathrm{B},{ }^{10}$ severe acute reactions have been described. ${ }^{34-37}$ In our study, 65 percent of the instances of discontinuation of liposomal amphotericin $B$ were due to a syndrome that included dyspnea, hypoxemia, urticaria, and chest, abdominal, or flank pain. By comparison, the only significant infusion-related reaction to voriconazole was transient photopsia, which was not associated with discontinuation of therapy.

More patients receiving liposomal amphotericin B had azotemia (defined as a serum creatinine level more than 1.5 times the base-line level), hypokalemia, or hypomagnesemia. However, there was no significant difference between the groups in the proportion of patients with serum creatinine levels of more than 
Table 5. Infusion-Related Reactions and Laboratory Abnormalities in Patients Treated With Voriconazole or Liposomal AMpHotericin B.

\begin{tabular}{|c|c|c|c|}
\hline \multirow[t]{2}{*}{ RESPONSE } & \multicolumn{2}{|r|}{$\begin{array}{l}\text { LIPOSOMAL } \\
\text { AMPHOTERICIN B } \\
\text { (N=422) }\end{array}$} & $\stackrel{P}{\mathbf{P}}$ \\
\hline & \multicolumn{2}{|c|}{ no./total no. (\%) } & \\
\hline \multicolumn{4}{|l|}{ Infusion-related reactions $\dagger$} \\
\hline Abnormal vision & $91(21.9)$ & $3(0.7)$ & $<0.001$ \\
\hline Chest pain & $1(0.2)$ & $17(4.0)$ & $<0.001$ \\
\hline Abdominal pain & $1(0.2)$ & $12(2.8)$ & 0.002 \\
\hline Back pain & 0 & $14(3.3)$ & $<0.001$ \\
\hline Flank pain & $1(0.2)$ & $8(1.9)$ & 0.038 \\
\hline Dyspnea & $3(0.7)$ & $37(8.8)$ & $<0.001$ \\
\hline Anaphylactoid reaction & 0 & $7(1.7)$ & 0.02 \\
\hline Flushing & $14(3.4)$ & $46(10.9)$ & $<0.001$ \\
\hline Sweating & $3(0.7)$ & $9(2.1)$ & \\
\hline Urticaria & $1(0.2)$ & $3(0.7)$ & \\
\hline Cyanosis & 0 & $2(0.5)$ & \\
\hline Chills & $57(13.7)$ & $126(29.9)$ & $<0.001$ \\
\hline Cardiac arrest & $\mathrm{l}(0.2)$ & 0 & \\
\hline Nausea & $39(9.4)$ & $53(12.6)$ & \\
\hline \multicolumn{4}{|l|}{ Laboratory abnormalities } \\
\hline \multicolumn{4}{|l|}{ Serum creatinine during therapy } \\
\hline$>1.5 \times$ base line & $43(10.4)$ & $80(19.0)$ & $<0.001$ \\
\hline$>2.0 \times$ base line & $29(7.0)$ & $32(7.6)$ & \\
\hline \multicolumn{4}{|c|}{$\begin{array}{l}\text { Nephrotoxicity with concomitant nephro- } \\
\text { toxic drugs } \ddagger\end{array}$} \\
\hline 0 or 1 drug & $42 / 372(11.3)$ & $37 / 381(9.7)$ & \\
\hline$\geqslant 2$ drugs & $6 / 42 \quad(14.3)$ & $16 / 241(39.0)$ & 0.01 \\
\hline$\geqslant 3$ drugs & $2 / 4 \quad(50.0)$ & $3 / 5 \quad(60.0)$ & \\
\hline \multicolumn{4}{|l|}{ Hypokalemia } \\
\hline Potassium $\leqslant 3.0 \mathrm{mmol} /$ liter & $68(16.4)$ & $131(31.0)$ & $<0.001$ \\
\hline Potassium $\leqslant 2.5 \mathrm{mmol} /$ liter & $10(2.4)$ & $21(5.0)$ & $<0.05$ \\
\hline \multicolumn{4}{|l|}{ Hypomagnesemia $\$$} \\
\hline Magnesium $\leqslant 0.75 \mathrm{mg} / \mathrm{dl}$ & $261(62.9)$ & $275(65.2)$ & \\
\hline Magnesium $\leqslant 0.60 \mathrm{mg} / \mathrm{dl}$ & $65(15.7)$ & $72(17.1)$ & \\
\hline \multicolumn{4}{|l|}{ Serum alkaline phosphatase } \\
\hline$>3 \times$ the base-line value & 0 & $2(0.5)$ & \\
\hline$>5 \times$ the base-line value $\|$ & $12(2.9)$ & $18(4.3)$ & \\
\hline \multicolumn{4}{|l|}{ Serum aspartate aminotransferase } \\
\hline$>3 \times$ the base-line value & 0 & 0 & \\
\hline$>5 \times$ the base-line value $\|$ & $37(8.9)$ & $27(6.4)$ & \\
\hline \multicolumn{4}{|l|}{ Serum alanine aminotransferase } \\
\hline$>3 \times$ the base-line value & $1(0.2)$ & 0 & \\
\hline$>5 \times$ the base-line value $\|$ & $29(7.0)$ & $34(8.1)$ & \\
\hline \multicolumn{4}{|l|}{ Serum bilirubin during therapy } \\
\hline$\geqslant 1.5 \times$ base line & $73(17.6)$ & $97(23.0)$ & 0.05 \\
\hline$\geqslant 3.0 \times$ base line & $40(9.6)$ & $46(10.9)$ & \\
\hline
\end{tabular}

* $\mathrm{P}$ values indicating significant differences are shown.

†A total of 10,398 infusions were prospectively monitored: 6053 in the voriconazole group and 4345 in the liposomal amphotericin B group.

$\ddagger$ Nephrotoxic drugs were aminoglycosides, cyclosporine, and foscarnet.

\$To convert the values for magnesium to millimoles per liter, multiply by 0.5 .

IFigures are for patients with base-line values 2 to 5 times the upper limit of normal.

$\|$ Figures are for patients with base-line values $<2$ times the upper limit of normal. 
two times base line, a result consistent with the substantially lower nephrotoxicity of liposomal amphotericin $\mathrm{B}$ in comparison with that of conventional amphotericin B. Voriconazole was not associated with any increase in the frequency of hepatic or renal abnormalities. The low frequency of hepatotoxicity with empirical therapy in our study may not pertain in patients undergoing more prolonged treatment for proven infection. In addition to its lower rates of nephrotoxicity and hepatotoxicity, the reliable oral bioavailability of voriconazole may make possible earlier hospital discharge and substantial cost savings in selected patients.

This study demonstrates that voriconazole, a second-generation triazole, is an appropriate agent for empirical antifungal therapy and that its use may reduce the frequency of proven breakthrough fungal infections, preserve renal function, and reduce the frequency of acute infusion-related toxic effects. Formulations of amphotericin B have been the standard of empirical antifungal therapy for nearly 20 years. As this study shows, a second-generation triazole can be used in lieu of amphotericin B for early antifungal therapy.

Supported in part by grants from the National Institute of Allergy and Infectious Diseases Mycoses Study Group (NOl-AI-65296) and Pfizer Global Research and Development.

Dr. Walsh reports receiving consulting fees from Pfizer in 2001.

\section{APPENDIX}

The following investigators, subinvestigators, and coordinators also participated in the study. United States - Baylor University Medical Center, Houston: E. Vance III, E. Agura, J.W. Fay, L. Pineiro, and B.-J. Chang; Beth Israel Deaconess Medical Center, Boston: J. Delaney; Floating Hospital for Children, Boston: C. Kretschmar; California Pacific Medical Center, San Francisco: D. Busch and L. Morello; Children's Hospital of Orange County, Orange, Calif: A. Arrieta; Children's Hospital of Pittsburgh, Pittsburgh: M. Green and T. Evangelista; Children's Hospital, Dana-Farber Cancer Institute, and Brigham and Women's Hospital, Boston: P.L. Hibberd and R.W. Finberg; Children's National Medical Center, Washington, D.C.: N. Seibel; Christiana Care Health Services, Newark, Del.: J.F. Reinhardt and S. Amato; City of Hope National Medical Center, Duarte, Calif.: J. Ito, B.R. Tegtmeier, R. Zabner, J.A. Zaia, M.R. O'Donnell, G. Somlo, R. Morgan, S.J. Forman, and K.R. Gilfillan; Columbia Presbyterian Medical Center, New York: B. Scully; Cooper Hospital and University Medical Center, Camden, N.J.: A. Reboli and L. McGlone; Fairview University Medical Center, Minneapolis: J. Van Burik; Florida Hospital, Orlando, Fla.: J. Hiemenz; Harper Hospital, Detroit: P. Chandrasekar, G. Alangaden, M. Varterasian, and M. Steigelman; Henry Ford Hospital, Detroit: N. Markowitz; Hoad Cancer Center, Newport Beach, Calif.: R.O. Dillman; Inova Institute of Research and Education, Falls Church, Va.: P. Francis; Johns Hopkins Hospital, Baltimore: C. Schwartz; Loyola University Medical Center, Maywood, Ill.: V. Yelandi, C. Cutrone, and O. Beltran; Mayo Clinic, Rochester, Minn.: S. Mueller; Montefiore Medical Center, Bronx, N.Y.: R. Gucalp, U. Malik, and P. Becker; Mount Sinai Medical Center, New York: L. Isola; MCUH Bone Marrow Unit: C. Oley, K. Candler, R.J. Smith, and L. Annateau; National Institute of Allergy and Infectious Diseases Mycoses Study Group, Birmingham, Ala.: C. Thomas; National Institutes of Health, Bethesda, Md.: M. Roden, R. Childs, J. Barrett, C. Dunbar, M. Bishop, D. Fowler, C. Castensportes, and J. Gea-Benacloche; New York Medical College, Valhalla, N.Y.: T. Ahmed, D. Holmgren, J. Ritacco, B. Oudheusden, and K. Ruhs; Pfizer Global Research and Development, Groton, Conn.: H. Boucher, M. Clements, C. Ewen, J. Chow, and R. Swanson; Rush-Presbyterian-St. Luke's Medical Center, Chicago: J.
Segreti, L.A. Proia, and M. Agnoli; Strong Memorial Hospital, Rochester, N.Y.: D.N. Korones and M. Benita-Weiss; Sutter Cancer Center, Sacramento, Calif.: V. Caggiano, A. Sayegh, and S. Mendenhall; Tulane University School of Medicine, New Orleans: D.M. Mushatt and K. Craig; UCLA Medical Center, Los Angeles: M. Territo; University of California at Davis, Sacramento: S.H. Cohen and W.E. Lippert; University of California at San Diego, San Diego: L. Rickman and S. Popovich; University of Oklahoma, Oklahoma City: R.G. Postier; University Hospitals of Cleveland, Cleveland: H.M. Lazarus and L. Slaughter; University of Kentucky, Lexington: D. Reece, G. Phillips, D. Howard, B. Plummer, M. Caldwell, D. Hargis, and S. Roberts; University Medical Center, Stony Brook, N.Y.: R. Parker; University of Michigan and Veterans Affairs Medical Center, Ann Arbor: I. Ryan, C. Kauffman, C. Chenoweth, and H.P. Erba; University of Mississippi Medical Center, Jackson: S. Chapman; University of North Carolina, Chapel Hill: J. Wiley, S.H. Gold, and R.P. Dunaway; University of Pennsylvania Medical Center, Philadelphia: K. Foley and R. Heigl; University of Texas M.D. Anderson Cancer Center, Houston: I.I. Raad, H. Manna, and D. Sumoza; University of Texas Health Science Center, Houston: T. Patterson; University of Utah, Salt Lake City: C. Morrison; University of Virginia Health Science Center, Charlottesville: M. Ross, C. Hess, M. Williams, and C. Harman; Vanderbilt University Medical Center, Nashville: J.S. Dummer; Walt Disney Memorial Cancer Institute and Florida Hospital Orlando, Orlando, Fla.: J.W. Hiemenz and S.K. Hiemenz; West Virginia University, Morgantown, W.Va.: S.G. Ericson, J.P. Lynch, C. Beall, E. Westin, M. Auber, P. Bunner, and R. Weisenborn. Canada - Health Sciences Center, Winnipeg, Man.: E. Bow and R. Loewen; Henderson General Hospital, Hamilton, Ont.: C. Rotstein; Hôtel-Dieu de Québec, Quebec, Que.: R. Pelletier, T. Jones, and F. Brisebois; Hôpital Maisonneuve-Rosemont, Montreal: F. Habel; Hôpital du St.-Sacrement, Ste.-Foy, Que.: R. Delage and J. Poulin; Hôpital Ste.-Justine, Montreal: A. Moghrabi and A. Proietti; Ottawa Hospital and University of Ottawa, Ottawa, Ont.: L. Radney, D. Garber, and L.B. Huebsch; Royal University Hospital, Saskatoon, Sask.: K.E. Williams, B.J.K. Tan, K.L. McClean, S.E. Sanche, B.A. Peters, and D. Mills; Queen Elizabeth II Health Sciences Center, Halifax, N.S.: S. Robinson; University of Alberta Hospitals, Edmonton: S. Shafran, D. Kunimoto, L. Larratt, B. Ritchie, A.R. Turner, A. Lindemulder, H. Lee, S. Roberts, and L. Mashinter. France - Hôpital Pitié-Salpêtrière, Paris: J.-P. Vernant and N. Dhedin; Hôtel Dieu, Paris: J.P. Marie and A. Vekhoff; Institut Gustave Roussy, Villejuif: J.-L. Pico and L. Contreras. India - Cancer Institute (WIA) Adyar, New Delhi: T.G. Sagar and S.G. Raman; Gujarat Cancer and Research Institute, Ahmedabad: P.M. Shaw, K.M. Patel, S.N. Shukla, A.S. Anand, K.P. Sajnani, and V.B. Parekh; Rotary Institute Cancer Hospital, New Delhi: V. Raina and U. Banerjee; Regional Cancer Center, Thiruvananthapuram: M.K. Nair, G. Narayanan, and K. Ratheesan; Tata Memorial Hospital, Mumbai: R. Gopal, S.H. Advani, T. Saikia, and P. Parikh. Italy - Policlinico Monteluce, Perugia: A. Del Favero, P. Furno, G. Barbabietola, S. Ballanti, G. Bucaneve, S. Dionisi, E. Burchielli, and M.L. Ottaviani; Università degli Studi di Napoli "Federico II," Naples: B. Rotol and M. Picardi; Ospedale Niguarda Ca' Granda, Milan: A.M. Nosari; Azienda Ospedaliere di Bologna, Policlinico S. Orsola, Malpighi, Bologna: P. Ricci, P. Tosi, E. Merla, and L. Valdre'; Trapianto Presidio Ospedaliero della ASL di Pescara, Pescara: G. Fioritoni, D. D’Antonio, S. Santarone, S. Di Ienno, and N. Toselli; Azienda Ospedaliera Bianchi-Melacrino-Morelli, Reggio Calabria: F. Nobile; Policlinico Universitario, Udine: M. Baccarani; Ospedalia Riuniti di Bergamo, Bergamo: T. Barbui, M. Buelli, F. Norbis, and L. Ruggeri. United Kingdom - Hammersmith Hospital, London: T. Rogers; Pfizer, Sandwich: H. Boucher and C. Ewen; Royal Free Hospital, London: H.G. Prentice, P.J. Paterson, H.A. McCullough, L.C. Herbert, and S.C. Grace; University College London Hospitals, London: S. Mackinnon and J. Wendon; Withington Hospital, Manchester: B. Oppenheim; Christie Hospital, Manchester: J.H. Scarffe, K.L. Bowyer, and E.C. Jacklin.

\section{REFERENCES}

1. Vartivarian SE, Anaissie EJ, Bodey GP. Emerging fungal pathogens in immunocompromised patients: classification, diagnosis, and management. Clin Infect Dis 1993;17:Suppl 2:S487-S491.

2. Andriole VT. Infections with Aspergillus species. Clin Infect Dis 1993 ; 17:Suppl 2:S481-S486.

3. Pannuti C, Gingrich R, Pfaller MA, Kao C, Wenzel RP. Nosocomial pneumonia in patients having bone marrow transplant: attributable mor tality and risk factors. Cancer 1992;69:2653-62.

4. Pizzo PA. Management of fever in patients with cancer and treatmentinduced neutropenia. N Engl J Med 1993;328:1323-32.

5. Hughes WT, Armstrong D, Bodey GP, et al. 1997 Guidelines for the use of antimicrobial agents in neutropenic patients with unexplained fever. Clin Infect Dis 1997;25:551-73. 
6. Pizzo PA, Robichaud KJ, Gill FA, Witebsky FG. Empiric antibiotic and antifungal therapy for cancer patients with prolonged fever and granulocytopenia. Am J Med 1982;72:101-11.

7. EORTC International Antimicrobial Therapy Cooperative Group. Empiric antifungal therapy in febrile granulocytopenic patients. Am J Med 1989;86:668-72.

8. Karp JE, Merz WG, Charache P. Response to empiric amphotericin B during antileukemic therapy-induced granulocytopenia. Rev Infect Dis $1991 ; 13: 592-9$

9. Rex JH, Walsh TJ, Sobel JD, et al. Practice guidelines for the treatment of candidiasis. Clin Infect Dis 2000;30:662-78.

10. Walsh TJ, Finberg RW, Arndt C, et al. Liposomal amphotericin B for empirical therapy in patients with persistent fever and neutropenia. N Engl J Med 1999;340:764-71.

11. Prentice HG, Hann IM, Herbrecht R, et al. A randomized comparison of liposomal versus conventional amphotericin $\mathrm{B}$ for the treatment of pyrexia of unknown origin in neutropenic patients. Br J Haematol 1997; 98:711-8.

12. Sheehan DJ, Hitchcock CA, Sibley CM. Current and emerging azole antifungal agents. Clin Microbiol Rev 1999;12:40-79.

13. Hossain MA, Ghannoum MA. New investigational antifungal agents for treating invasive fungal infections. Expert Opin Investig Drugs 2000;9: 1797-813

14. Malik IA, Moid I, Aziz Z, Khan S, Suleman M. A randomized com parison of fluconazole with amphotericin B as empiric anti-fungal agents in cancer patients with prolonged fever and neutropenia. Am J Med 1998; 105:478-83

15. Viscoli C, Castagnola E, Van Lint MT, et al. Fluconazole versus amphotericin $\mathrm{B}$ as empirical antifungal therapy of unexplained fever in granulocytopenic cancer patients: a pragmatic, multicentre, prospective and randomised clinical trial. Eur J Cancer 1996;32A:814-20.

16. Winston DJ, Hathorn JW, Schuster MG, Schiller GJ, Territo MC. A multicenter, randomized trial of fluconazole versus amphotericin B for empiric antifungal therapy of febrile neutropenic patients with cancer. Am J Med 2000;108:282-9.

17. Boogaerts $M$, Winston DJ, Bow EJ, et al. Intravenous and oral itraconazole versus intravenous amphotericin $\mathrm{B}$ deoxycholate as empirical the apy for persistent fever in neutropenic patients with cancer who are receiving broad-spectrum antibacterial therapy: a randomized, controlled trial. Ann Intern Med 2001;135:412-22.

18. Schlamm HT, Corey L, Brown W, et al. Voriconazole for "salvage" treatment of invasive aspergillosis. Presented at the 38th Annual Meeting of the Infectious Diseases Society of America, New Orleans, September 7-10, 2000. abstract.

19. Walsh TJ, Lutsar TI, Ghahramani P, et al. Efficacy of safety of voriconazole (VORI) and the treatment of invasive fungal infection in children. Presented at the 40th Interscience Conference on Antimicrobial Agents and Chemotherapy, Toronto, September 17-20, 2000. abstract.

20. Perfect J, González-Ruiz A, Lutsar I, et al. Voriconazole (VORI) for the treatment of resistant and rare fungal pathogens. Presented at the 38th Annual Meeting of the Infectious Diseases Society of America, New Orleans, September 7-10, 2000. abstract.

21. Ascioglu S, Rex JH, de Pauw B, et al. Analysis of definitions used in clinical research on invasive fungal infections: consensus proposal for new, standardized definitions. Clin Infect Dis (in press).

22. Reference method for broth dilution antifungal susceptibility testing of yeasts: tentative standard. Wayne, Pa.: National Committee for Clinical Laboratory Standards, 1997. (NCCLS document no. M27-A.)

23. Espinel-Ingroff A, Bartlett $M$, Bowden R, et al. Multicenter evaluation of proposed standardized procedure for antifungal susceptibility testing for filamentous fungi. J Clin Microbiol 1997;35:139-43.

24. Gage R, Stopher DA. A rapid HPLC assay for voriconazole in human plasma. J Pharm Biomed Anal 1998;17:1449-53.

25. Herbrecht R, Denning DW, Patterson TF, et al. Open, randomized comparison of voriconazole (VRC) and amphotericin $\mathrm{B}(\mathrm{AmB})$ followed by other licensed antifungal therapy of invasive aspergillosis (IA). In: Program and abstracts of the 4lst Interscience Conference on Antimicrobial Agents and Chemotherapy, Chicago, December 16-19, 2001. Washington, D.C.: American Society for Microbiology (in press). abstract.

26. McGinnis MR, Pasarell L, Sutton DA, Fothergill AW, Cooper CR Jr, Rinaldi MG. In vitro activity of voriconazole against selected fungi. Med Mycol 1998;36:239-42.

27. Espinel-Ingroff A. In vitro activity of the new triazole voriconazole (UK-109-496) against opportunistic filamentous and dimorphic fungi and common and emerging yeast pathogens. J Clin Microbiol 1998;36:198-202. 28. Bergogne-Berezin E. New concepts in the pulmonary disposition of antibiotics. Pulm Pharmacol 1995;8:65-81.

29. Ribaud $P$, Chastang $C$, Latge J-P, et al. Survival and prognostic factors of invasive aspergillosis after allogeneic bone marrow transplantation. Clin Infect Dis 1999;28:322-30.

30. Ribrag V, Dreyfus F, Venot A, Leblong V, Lanore JJ, Varet B. Prognostic factors of invasive pulmonary aspergillosis in leukemic patients. Leuk Lymphoma 1993;10:317-21.

31. Patterson TF, Kirkpatrick WR, White $M$, et al. Invasive aspergillosis: disease spectrum, treatment practices, and outcomes. Medicine (Baltimore) 2000;79:250-60.

32. Guiot HFL, Fibbe WE, van 't Wout JW. Risk factors for fungal infection in patients with malignant hematologic disorders: implications for em pirical therapy and prophylaxis. Clin Infect Dis 1994;18:525-32.

33. Rex JH, Bennett JE, Sugar AM, et al. A randomized trial comparing fluconazole with amphotericin B for the treatment of candidemia in patients without neutropenia. N Engl J Med 1994;331:1325-30.

34. Arning M, Heer-Sonderhoff AH, Wehmeier A, Schneider W. Pulmonary toxicity during infusion of liposomal amphotericin $\mathrm{B}$ in two patients with acute leukemia. Eur J Clin Microbiol Infect Dis 1995;14:41-3.

35. Wong-Beringer A, Jacobs RA, Guglielmo BJ. Lipid formulations of amphotericin B: clinical efficacy and toxicities. Clin Infect Dis 1998;27:603-18. 36. Walsh TJ, Yeldandi V, McEvoy M, et al. Safety, tolerance, and pharmacokinetics of a small unilamellar liposomal formulation of amphotericin B (AmBisome) in neutropenic patients. Antimicrob Agents Chemother 1998; 42:2391-8.

37. Johnson MD, Drew RH, Perfect JR. Chest discomfort associated with liposomal amphotericin B: report of three cases and review of the literature. Pharmacotherapy 1998;18:1053-61.

Copyright (C) 2002 Massachusetts Medical Society.

234 • N Engl J Med, Vol. 346, No. 4 • January 24, $2002 \cdot$ www.nejm.org 